Studies such as this comparing methods of measurement should be analysed by taking the differences between the paired reading and calculating the mean and standard deviation of that set. The mean of the differences then gives a measure of accuracy or bias and the standard deviation gives a measure of precision. ${ }^{1}$

E C Coles R G NewCOMBE

Department of Medical Statistics,

Heath Park, Cardiff CF4 4XN

'Altman DG. Statistics and ethnics in medical re

search. Analysing data. Br Med $\mathcal{f} 1980 ; 281$ :1473-5.

\section{Effect of environment on blood pressure}

SIR,-In the study by Dr M A Young and others (16 April, p 1235) it could be postulated that patients who went home on the same day as they had arterial cannulation would be more anxious and have higher blood pressures than patients who went home on the second day of the study. It would be interesting to be told the actual differences between home and hospital blood pressure recordings on the first and second days of the study and whether these differences can be considered significant.

Tewin, Herts

Kevin A Cleur

${ }_{*}^{*}$ *We sent a copy of this letter to Dr Young, who replies below.-ED, $B M$ F.

SIR,-Patients who spent the first day at home were indeed rather more hypertensive than those who spent the first day in hospital, but the differences in systolic and diastolic pressure were not statistically significant. Average total intra-arterial pressure in the group who spent the first day at home was 142/89 (mean 107) $\mathrm{mm} \mathrm{Hg}$ (hospital) and 160/91 (mean 114) $\mathrm{mm} \mathrm{Hg}$ (home). In the group who spent the first day in hospital these values were 133/82 (mean 99) $\mathrm{mm} \mathrm{Hg}_{\mathrm{g}}$ (hospital) and 144/85 (mean 105) $\mathrm{mm} \mathrm{Hg}$ (home). Cuff pressure showed similar but less striking trends: values for those who spent the first day at home were $159 / 90$ (mean 113) $\mathrm{mm} \mathrm{Hg}$ (hospital) and 175/101 (mean 126) $\mathrm{mm} \mathrm{Hg}$ (home), and for those who spent the first day in hospital values were $157 / 84$ (mean 108) $\mathrm{mm} \mathrm{Hg}$ (hospital) and 168/94 (mean 119) $\mathrm{mm} \mathrm{Hg}$ (home). From these rather confusing figures we can deduce that both groups had higher mean intra-arterial and cuff pressures at home; the degree to which these pressures were higher at home was the same in the two groups ( $7 v 6 \mathrm{~mm} \mathrm{Hg}$ (intra-arterial) and $13 v 11 \mathrm{~mm} \mathrm{Hg}$ (cuff) respectively)

Thus the blood pressure of both subgroups behaved similarly within the different environments.

M A Young

Department of Cardiovascular Medicine,

East Birmingham Hospital,

Bordesley Green East,
Birmingham B9 5ST

\section{Should homosexuals be vaccinated against hepatitis $B$ virus?}

SIR,-The cost effectiveness of vaccinating male homosexuals against hepatitis $B$ has now been demonstrated. Professor $\mathbf{M}$ W Adler and others (21 May, p 1621) were admirably precise and restricted themselves to close argument of costs and benefits. The idea of making the vaccine unavailable for male homosexuals is also indefensible. Much of the vaccine has been obtained from male homosexuals; and this was the first population in which its efficacy was properly shown. The widespread cooperation of male homosexuals in the development of the vaccine deserves recognition.

\section{MARTIN R HAMilton-FarRell Gay Medical Association (UK), \\ London WCIN 3XX}

SIR,-May I comment on the cost benefit analysis by Professor $M$ W Adler and others (21 May, p 1621)? Although the cash value of sickness absence and earnings lost through premature death are of undoubted importance when arguing for an overall increase in Health Service expenditure, they should be a secondary consideration when deciding between competing priorities for expenditure within the Health Service.

May I suggest that when comparing alternative programmes, the appropriate "benefit" is the years of life saved by preventing avoidable deaths plus the increased quality of life both for the patient and his relatives that results from the relief of suffering and disability through medical and surgical procedures and by hospital and community care.

I calculate that the cost per year of life saved (including a weighting for quality of life) is $£ 50$ for routine childhood immunisation or routine surgery, $£ 100$ or $£ 200$ for acute medical and maternity services, to over $£ 5000$ for head injury, haemodialysis, or long stay hospital care.

The cost to the Health Service of the hepatitis programme is between $£ 300$ and $£ 600$ per year of life saved (including a weighting for quality of life). The hepatitis programme might therefore expect a priority below acute medical and maternity services, but considerably above head injury, haemodialysis, and long stay hospital care.

Leicestershire Health Authority,

J J JONES

Leicester LE

\section{Identical twins with identical} vesicoureteric reflux

SIR,-We read with interest the report by Professor D N S Kerr and Dr P M Pillai (16 April, p 1245) and recalled another pair of identical twins who provide further support for the suggestion that factors other than the presence of vesicoureteric reflux dictate the natural history of chronic pyelonephritis.

In 1975 one of the twins, aged 20, had hypertension and proteinuria during her pregnancy. After delivery, intravenous urography showed changes consistent with chronic pyelonephritis due to reflux nephropathy: the left kidney was shrunken with dilated calyces and the right showed severe cortical thinning, dilated calyces, and a dilated ureter. Her creatinine clearance was $27 \mathrm{ml} / \mathrm{min}$. Although her hypertension was initially treated, she was then lost to follow up. In 1982 she was referred to the Hammersmith Hospital with end stage renal failure. After initial treatment with peritoneal dialysis, she had a successful renal transplant from her mother.

Her identical twin sister also had an intravenous urogram in 1975, which showed changes consisten with chronic pyelonephritis with reflux: her left kidney was normal, but on the right kidney the uppermost calyx was clubbed, and both ureters were dilated and contained residual contrast afte voiding. This twin was normotensive in 1975 and also in 1982, when she was reviewed; at that time a repeat intravenous urogram showed little change from 1975, her plasma creatinine concentration was normal, and there was no proteinuria.

Clearly these identical twins have the same underlying disorder-namely, vesicoureteric reflux-but the subsequent natural history has been strikingly different. Any additional injurious factor must have been present earlier in life because by the time both were aged 20 the degree of renal scarring was very different in the two cases. The poor prognosis of the first patient could perhaps have been predicted by the presence of proteinuria, renal impairment, and hypertension.' The finding of vesicoureteric reflux in monozygotic twins is not a new observation, ${ }^{2} 3$ but the variation in natural history is remarkable.

C G WINEARLS C R K HIND

Department of Medicine Royal Postgraduate Medical School London W12 $0 \mathrm{HS}$

' Arze RS, Ramos JM, Owen JP, et al. The natural history of chronic pyelonephritis in the adult. $Q \mathcal{F}$ Med

2 Stephens FD, Joske RA, Simmons RT. Megaureter with vesicoureteric reflux in twins. Aust NZ $\mathcal{J}$ Surg 1955;24:192-4

- Hampel N, Levin DR, Gersh I. Bilateral vesicoureteral reflux with pyelonephritis in twins. $\mathrm{Br} \mathcal{F}$ Urol 1975;47:535-7.

Treatment of angina pectoris with nifedipine

SIR,-In their paper on the importance of dose titration of nifedipine in the treatment of angina pectoris, Dr J Deanfield and others (7 May, p 1467) failed to discuss their most interesting observation-namely, the 15-fold variation in nifedipine plasma concentration in 10 patients given $30-40 \mathrm{mg}$ nifedipine three times daily. While there are as yet few data associating nifedipine plasma concentration with therapeutic or toxic effects, ${ }^{1}$ such relations are likely to exist for the following reasons: firstly, after oral administration nifedipine elimination results from metabolism and not excretion of the unchanged drug ${ }^{2}$; and, secondly, the principal human metabolites of nifedipine have no pharmacological activity.

The highly variable nifedipine plasma concentrations reported by Dr Deanfield and others may be due to differences between patients in first pass metabolism of the drug. In 12 normal subjects who received nifedipine both orally and intravenously, the bioavailability of the drug varied approximately between 0 and $90 \%$ after a single oral dose. ${ }^{1}$ This is most likely to represent variable first pass metabolism rather than absorption difficulties since, as the data of Dr Deanfield and others show, variation in plasma concentration increases appreciably with increasing dose, a sign of saturation of presystemic metabolism.

Nifedipine is metabolised in man principally by oxidation. ${ }^{2}$ It is common to find wide variation between subjects in metabolic oxidation of drugs, as, for example, is the case with debrisoquine, ${ }^{45}$ where the variability in drug handling stems from pharmacogenetic differences between subjects. About one in 10 persons in the United Kingdom is virtually unable to effect the first passage metabolism of debrisoquine and many other drugs. Thus, patients who inherit this poor metaboliser phenotype can be thought of as being compromised by their drug treatment when the drug accumulates to uncommonly high concentrations. A good example of the foregoing is that of another calcium antagonist, perhexiline (Pexid), which has an inordinately long half life 